15 Poulton J, Morten K, Brown G, Bindoff L. Are duplications of mitochondrial DNA characteristic of Kearns-Sayre syndrome? Human Molecular Genetics 1994; 3: 947-51.

16 Prezant TR, Agapian JV, Bohlman MC, et al. Mitochondrial ribosomal RNA mutation associated with both antibiotic-induced and non-syndromic deafness. Nature Genet 1993; 4: 289-94.

17 Fischel-Ghodsian N, Prezant TR, Bu X, Oztas S. Mitochondrial ribosomal RNA gene mutation in a patient with sporadic aminoglycoside ototoxicity. Am f Otolaryngol 1993; 14: 399-403.

18 Anonymous. Mitochondrial encephalomyopathies: gene location. Neuromuscul Disord 1995; 5: IX-XII.

19 Zeviani M, Servidei S, Gellera C, Bertini E, DiMauro S, DiDonato S. An autosomal dominant disorder with multiple deletions of mitochondrial autosomal dominant disorder with multiple deletions of mitoch

20 Casademont J, Barrientos A, Cardellach F, et al. Multiple deletions of mtDNA in two brothers with sideroblastic anemia and mitochondrial myopathy and in their asymptomatic mother. Human Molecular Genetics 1994; 3: 1945-9.

\section{Genetic testing of children}

Presymptomatic diagnosis of some individuals at risk of genetic disease is possible by clinical examination or by simple investigations (for example, sweat test for cystic fibrosis, haemoglobin electrophoresis for haemoglobinopathies, creatine phosphokinase levels for Duchenne and Becker muscular dystrophy, ultrasound screening for adult polycystic kidney disease). Similarly, carriers of recessive disorders (for example, haemoglobinopathies) and balanced chromosomal rearrangements can be identified. In the assessment of carrier status in girls from Duchenne muscular dystrophy families, it has been traditional to leave testing until teenage. For other disorders, testing has been performed earlier - sometimes inadvertently (for example, with prenatal diagnosis, carriers of balanced chromosome rearrangements are detected in utero).

Recently, the mapping and cloning of a number of medically important genes has greatly increased both the number of disorders for which tests are possible and the accuracy of those tests. In some situations, it is important that the carrier state is identified even in fetal life (for example, female carriers of the $\mathrm{X}$ linked condition ornithine transcarbamylase deficiency can frequently be symptomatic and require close postnatal observation) but what about all the other plethora of situations? Is it in the child's interests for this information to be known? Harper and Clarke raised these concerns in a Lancet article after their experience of requests for presymptomatic testing for Huntington's disease. ${ }^{1}$ Their protocol only allowed testing of adults upon their own request and testing of children was refused, including requests from adoption agencies. As a result of this concern, the Clinical Genetics Society (UK) convened a working party to consider the issues and their report has recently been published. ${ }^{2}$

The remit of the working party was to examine current attitudes and practice with regard to this issue, focus attention on any difficulties raised by the genetic testing of children, and make appropriate recommendations about future practice. The working party included representatives from clinical and laboratory genetics, paediatrics, law, and psychiatry. They sent an initial questionnaire to approximately $3000-4000$ health professionals $(512$ replied), which included 990 consultant paediatricians of whom $337(34 \%)$ replied. Some months later, a supplementary questionnaire was sent to the same 990 consultants of whom 260 responded.
21 Moraes CT, Shanske S, Tritschler HJ, et al. $\mathrm{mtDNA}$ depletion with variable tissue expression: a novel genetic abnormality in mitochondrial diseases. Am $\mathcal{F}$ Hum Genet 1991; 48: 492-501.

22 Tritschler H-J, Andreetta F, Moraes CT, et al. Mitochondrial myopathy of childhood associated with depletion of mitochondrial DNA. Neurology 1992; 42: 209-17.

23 Brown GK. Pyruvate dehydrogenase E1 alpha deficiency. 7 Inherit Metab Dis 1992; 15: 625-33.

24 Holt IJ, Harding AE, Petty RK, Morgan-Hughes JA. A new mitochondrial disease associated with mitochondrial DNA heteroplasmy. Am 7 Hum Genet 1990; 46: 428-33.

25 Tatuch Y, Robinson B. The mitochondrial DNA mutation at 8993 associated with NARP slows the rate of ATP synthesis in isolated lymphoblast mitochondria. Biochem Biophys Res Commun 1993; 192: 124-8.

26 de Vries DD, van Engelen BG, Gabreels FJ, Ruitenbeek W, van Oost BA. A second missense mutation in the mitochondrial ATPase 6 gene in Leigh's syndrome. Ann Neurol 1993; 34: 410-2.

\section{Current practice and attitudes}

The predominant view expressed in the survey was that requests for testing should only be considered if initiated by the child's parents or medical advisers, although $50 \%$ of the paediatricians felt that adoption agencies had the right to request testing (even if the result would have no direct health benefit for the child) as opposed to $28 \%$ of geneticists. Attitudes varied from disorder to disorder. Where some intervention might be indicated in childhood, either therapeutic or via surveillance for complications, most geneticists and paediatricians were in favour of testing (for example, Marfan's syndrome, hyperlipidaemias, polyposis coli, von Hippel-Lindau syndrome). For some disorders where onset could occur in childhood, a small majority of geneticists and a larger majority of paediatricians would perform a test (for example, adult polycystic kidney disease, Becker muscular dystrophy). There was another group of conditions where the majority of paediatricians but a minority of geneticists would test (for example, myotonic dystrophy, facioscapulohumeral muscular dystrophy).

The most striking difference in attitude is apparent when respondents were asked if they would test a 5 year old child at the parents' request for Huntington's disease and prion dementia. Only two out of 49 geneticists who responded would test for Huntington's disease compared with 100 out of 189 paediatricians and none of the geneticists would test for prion dementia but 66 out of 114 paediatricians would. The views of those paediatricians and geneticists who would test are at variance with the working party's conclusion that predictive testing for an adult onset disorder should generally not be undertaken if the child is healthy and there are no useful medical interventions if the test proved positive. This is particularly important as the legal view expressed in the document is that it may be regarded as negligent to test a child for Huntington's disease (except in very particular circumstances) given the general consensus that it is unwise to do so.

There was a wide range of views about testing children for carrier status for cystic fibrosis and balanced chromosomal translocations and certainly it appeared to be common practice among paediatricians to test the healthy siblings of their affected patients. Geneticists as a group were less likely to view parental wishes alone as sufficient to justify testing. 
A brief survey of family support groups showed a range of attitudes. Overall, more of the replies were opposed to both presymptomatic and carrier detection in childhood than in favour. In contrast, a questionnaire completed by parents of 114 children attending a cystic fibrosis clinic revealed that $91 \%$ of patients felt that they had a right to know the carrier status of their children and $90 \%$ stated that they would like to know, if the facility was available. $^{3}$

\section{Ethical considerations}

Testing in childhood removes the right of children to decide for themselves whether or not to be tested when they reach adult life. This is of prime importance for those burdensome disorders which are late onset and untreatable and where many adults decline the offer of a test (for example, Huntington's and Alzheimer's disease and prion dementia). In addition the confidentiality to which an adult would be entitled is breached by disclosing results to the child's parents. Such testing also breaches the policy of providing counselling before, during, and after the testing process. There is also the concern that a positive test may result in future discrimination by insurance companies and employers.

Clearly these considerations do not apply to the large number of disorders for which testing would be in the child's interest because of treatment or surveillance for complications which could arise in childhood.

\section{Psychological considerations}

Could testing damage a child's self esteem, distort the family's perceptions of the child, or affect the child's capacity to form future relationships? There is very little information available on which to answer these questions. The working party quote studies in Tay-Sachs disease, ${ }^{4}$ sickle cell disease, ${ }^{5}$ and $\alpha_{1}$-antitrypsin deficiency ${ }^{6}$ to suggest that positive carrier screening tests can result in some of the above problems. However, some of this evidence is of doubtful significance - in the sickle cell survey, $10 \%$ of carriers were unable to state that being a carrier would not damage their health, but there was no record that this resulted in psychological disturbance. There were psychological problems for parents whose children were detected as having $\alpha_{1}$-antitrypsin deficiency in a newborn screening programme, but many of these families appear to have had inadequate counselling and information. The problems inherent in newborn screening programmes may well not apply to the situations under consideration here.

In the survey of parents of children with cystic fibrosis, $85 \%$ of the parents said that if they knew that their child was a carrier it would not affect the child's upbringing. ${ }^{3}$ The authors felt that this was not surprising given that the parents, being carriers themselves, would realise that carrier status did not entail any risk to health. Ten per cent of those questioned did feel that such knowledge would affect the child's upbringing but it is not stated in what way this would be affected.

Objective evidence for possible disturbance does come from studies in families affected by Huntington's disease, where persons are sometimes singled out for no rational reason as being destined to develop the disorder. Such family 'preselection' has been recognised as having potentially adverse effects on the emotional development of the unfortunately labelled child. ${ }^{7}$ One could envisage this being an even greater problem if a test confirmed the family dynamic that had selected one child as the 'victim'.
Could there be psychological benefits to testing? Having a diagnosis may enable parents to adjust to the circumstances and plan the disclosure of the news to their children. In my experience, this is the most common reason for parents to request testing. If a child is found to be unaffected, this obviates the need for discussing and arranging testing when the child is older, especially in the emotionally difficult teenage years. In the event of a positive result, there may be advantages to the child in the parents being able to break the news over a period of time, according to the child's developmental age. This approach has been described in the XY female. ${ }^{8}$ Testing might foster openness in some families and the resolution of parental anxiety might provide a healthier emotional environment. In other families the opposite effect might occur.

As discussed by Marteau, ${ }^{9}$ there are very few data on which to weigh up these considerations and the need for research in this area is essential. Marteau comments that any documentation needs to be qualified by the type and amount of counselling provided as well as the resources of individual families. It will also be necessary to document the consequences of not meeting requests for testing.

\section{Legal considerations}

Parental decisions about testing should be made according to whether the child will benefit, rather than to relieve parental anxiety. Decisions about testing must be taken jointly by the parents and professionals and testing cannot be carried out without parental consent, unless the child is considered able to give consent him/herself. The view expressed in the report is that health professionals can refuse to test if it is considered inappropriate and not in the child's best interests. Similarly, health professionals are not obliged to reveal information on the genetic status of a child when they believe it would harm the well being of the child.

\section{Practical considerations}

It could be argued that testing in childhood may obviate the need for arranging follow up but there is still the obligation to provide counselling later on. How can this responsibility be discharged? One possibility is to transfer the responsibility to the parents or to the general practitioner to arrange counselling at the appropriate age but these are not entirely satisfactory options. The best but most expensive option is to establish genetic family registers, whereby contact is maintained with the family and recall arranged at a suitable time. The most cost effective register system is one confined to a few disorders that are serious and carry a high genetic risk to the next generation, that is some late onset autosomal dominant disorders, serious $\mathrm{X}$ linked recessive disorders, and balanced chromosome rearrangements.

\section{Adoption}

The report suggests that in general there would be no indication to test an adopted child any earlier than one would test a birth child within a family. Special problems are, however, recognised especially where it proves difficult to find adoptive parents because of the genetic risk. It would seem best to find adopters who can accept the child as a whole and subsequently participate in any testing at the appropriate time but if this does not prove possible, decisions about genetic testing may need to be reconsidered in the light of the child's overall best interests. Hopefully such situations will be rare. 


\section{Recommendations}

As indicated above, the working party concluded that testing for untreatable adult onset disorders would be inappropriate. On other issues the advice of the working party was less definitive - a case can be made for genetic testing in some disorders where there is usually an adult onset but where there may be childhood implications, for example adult polycystic kidney disease (where screening by blood pressure checks and ultrasound is frequently performed) and myotonic dystrophy (where there may be anaesthetic implications). It is more contentious when one considers carrier detection for recessive disorders (for example, cystic fibrosis) and balanced familial chromosome translocations. The working party concludes that it may be wiser to defer testing in these circumstances until the child is able to understand the issues and requests testing in person. Inadvertent testing at prenatal diagnosis should be avoided if possible.

There is the recognition that there is an obligation on the health care system and the family to ensure that testing is offered when the child is older. There is also a recommendation that where testing has or is performed that psychosocial evaluation of the impact of the test on the child and the family would be useful so that future policy can be guided by evidence rather than conjecture.

\section{Conclusion}

The report recognises that some of these latter statements in particular are contentious and welcomes an informed debate on the issues. Can a consensus be reached? The working party believes this to be important especially if testing becomes more widely available through commercial laboratories which may pay little respect to the goal of coupling laboratory testing with the provision of genetic counselling and support. Paediatricians have an important role in the debate - the working party report provides an excellent starting point. This annotation will hopefully provide a further stimulus for paediatricians to comment.

In the meantime, what is good practice? Close liaison between paediatricians and their local colleagues in clinical and laboratory genetics is important when faced with these requests. In those situations where it is deemed appropriate to offer presymptomatic testing or to test a child for carrier status, it is important for the paediatrician or geneticist to discuss the possible pros and cons of testing with the family so that a fully informed decision is reached. Follow up support and counselling should be available to the families especially in the event of a positive test result and a clear arrangement made with the family to offer counselling to the child at appropriate stages in the future. Similarly a follow up arrangement should be made for those families where the decision is made not to test, ideally with a computerised family register.

University of Liverpool,

ALAN FRYER

Regional Clinical Genetics Service,

Royal Liverpool University Hospital,

Liverpool L69 3BX

1 Harper PS, Clarke A. Should we test children for 'adult' genetic diseases? Lancet 1990; 335: 1205-6.

2 The genetic testing of children. Report of a working party of the Clinical Genetics Society (UK). $\mathcal{f}$ Med Genet 1994; 31: 785-7.

3 Balfour-Lynn I, Madge S, Dinwiddie R. Testing carrier status in siblings of patients with cystic fibrosis. Arch Dis Child 1995; 72: 167-8.

4 Marteau TM, van Duijn M, Ellis I. Effects of genetic screening on perceptions of health: a pilot study. 7 Med Genet 1992; 29: 24-6.

5 Loader S, Sutera CJ, Segelman SG, Kozyra A, Rowley PT. Prenatal haemoglobinopathy screening. IV. Follow-up of women at risk for a child with a globinopathy screening. IV. Follow-up of women at risk for a child with a
clinically significant haemoglobinopathy. Am I Hum Genet 1991; 49: 1292-9.

6 Thelin T, McNeil TF, Aspergren-Jansson E, Sveger T. Psychological consequences of neonatal screening for alpha-1 antitrypsin deficiency. Acta Paediatr Scand 1985; 74: 787-93.

$7 \mathrm{Kessler}$ S. Invited essay on the psychological aspects of genetic counselling. V. Preselection: a family coping strategy in Huntington disease. Am $\mathcal{J}$ Med Genet 1988; 31: 617-21.

8 Goodall J. Helping a child to understand her own testicular feminisation. Lancet 1991; 337: 33-5.

9 Marteau T. The genetic testing of children. $f$ Med Genet 1994; 31: 743. 